\section{International Scientific Journal Theoretical \& Applied Science}

\author{
p-ISSN: 2308-4944 (print) e-ISSN: 2409-0085 (online) \\ Year: 2017 Issue: $06 \quad$ Volume: 50
}

Published: $30.06 .2017 \quad \underline{\text { http://T-Science.org }}$

\section{Georgy Vasil'evich Tokmazov}

Associate professor,

Candidate of Pedagogical Science,

Professor Department of Mathematics,

State Maritime University Admiral Ushakov, tokmazov@mail.ru

SECTION 21. Pedagogy. Psychology. Innovation in Education

\title{
ORGANIZATION OF EARTH METRIC ANALYSIS STUDENTS TRAINING AND STUDY SKILLS IN THE PROCESS OF STUDYING THE COURSE OF HIGHER MATHEMATICS
}

\begin{abstract}
The main problem of the study of the organization of the erymometric analysis of students' learning and research skills in the course of studying the course of higher mathematics is established by the modern models of organization of production in a basic form that simulates the problem solved through the stages of research: the establishment of a universal scheme for the process of the age-Research skills of students; The definition of a method for modeling the problem of the formation of the ageometric analysis of students' learning and research skills; The establishment of the form of a given result of the uremometric analysis of students 'learning and research skills, which makes it possible to determine the erymometric analysis of the optimal teaching and research skills for the formation of students' knowledge in the course of studying the course of higher mathematics

Key words: eryonometrics, analysis, educational and research skills, the model of production organization, higher mathematics.

Language: Russian

Citation: Tokmazov GV (2017) ORGANIZATION OF EARTH METRIC ANALYSIS STUDENTS TRAINING AND STUDY SKILLS IN THE PROCESS OF STUDYING THE COURSE OF HIGHER MATHEMATICS. ISJ Theoretical \& Applied Science, 06 (50): 128-132.

Soi: http://s-o-i.org/1.1/TAS-06-50-17 Doi: crossef https://dx.doi.org/10.15863/TAS.2017.06.50.17
\end{abstract}

УДК 372.851

\author{
ОРГАНИЗАЦИЯ ЭРЕВНОМЕТРИЧЕСКОГО АНАЛИЗА \\ УЧЕБНО-ИССЛЕДОВАТЕЛЬСКИХ УМЕНИЙ СТУДЕНТОВ \\ В ПРОЦЕССЕ ИЗУЧЕНИЯ КУРСА ВЫСШЕЙ МАТЕМАТИКИ
}

Аннотация: Рассмотрены основные проблема исследования организачии эревнометрического анализа учебно-исследовательских умений студентов в процессе изучения курса высшей математики, которые устанавливаются современными моделями организации производства в базисной форме, моделирующей данную проблему, решаемую через этапь исследования: установление всеобщей схемы прочесса эревнометрического анализа учебно-исследовательских умений студентов; определение метода моделирования проблемы формирования эревнометрического анализа учебно-исследовательских умений студентов; установление формы заданного результата эревнометрического анализа учебноисследовательских умений студентов, что позволяет определить эревнометрический анализ оптимальных учебно-исследовательских умений по формированию знаний студентов в прочессе изучения курса высшей математики.

Ключевые слова: эревнометрика, анализ, учебно-исследовательские умения, модель организации производства, высиая математика.

\section{Introduction}

Проблема исследования организации эревнометрического анализа учебноисследовательских умений студентов в процессе изучения курса высшей математики устанавливается современными моделями организации производ-ства в базисной форме, которая может моделировать данную проблему. Дальнейшее развитие проблемы формирования учебно-исследовательских умений требует интеграции и концентрации научного потенциала в едином предмете научного исследования, 
который представляет собой ЭРЕВНОМЕТРИКУ науку о методологии исследовательской деятельности в процессе изучения математики при непрерывной общеинженерной подготовке специалистов на базе обобщённых познавательных действий $[1,2]$.

Эревнометрический подход к анализу формирования исследовательских действий требует создания обобщённых схем скоростных исследовательских навыков, которые ориентируются на обобщённые циклы исследовательских умений, интегральные схемы исследовательских исследовательских действий и соответствую формообразования активности. Это требует единого генетического принципа существования и развития всего эревнометрического подхода на основе принципа алигорамности - обобщённого скоростного принципа исследовательских процессов через дифференциальные адаптивные формы его представления [3,4].

Анализ принципа алигорамности при эревнометрическом анализе образовательных объектов возникает через структурное представление каждой формы образовательных объектов: интериористическая образовательная пара (преподаватель-студент), экстериористическая образовательная пара (студент-преподаватель), самообразование (студент-студент), самоусовершенствование (преподаватель-преподаватель). В каждом случае возникает образовательная ячейка исследовательского умения направлен-ная на формирование смыслообразования, принятия учебного задания, ориентировки в нём, решение исследовательской задачи, организация контроля решения и поиск новых скоростных методов решения исследовательской задачи $[5,6]$.

При этом возникают собственные принципы и методы эревнометрического анализа. При этом задаются следующие этапы исследования: 1) установление всеобщей схемы процесса эревнометрического анализа учебноисследовательских умений студентов; 2) определение метода моделирования проблемы формирования эревнометрического анализа учебно-исследовательских умений студентов; 3) установление формы заданного результата эревнометрического анализа учебноисследовательских умений студентов. Это позволяет определить эревнометрический анализ оптимальных учебно-исследовательских умений по формированию знаний студентов в процессе изучения курса высшей математики $[7,8]$.

\section{Materials and Methods}

Исследование эревнометрического анализа

организации исследовательских умений студентов в процессе изучения курса высшей математики ориентируется на выполнение общего метода реализации обобщённой схемы эревнометризма, отражающей единство предметных и активных форм познавательной деятельности студентов алигораметрического содержания. На первых занятиях по курсу математики учащимся предъявляются главные направления реализации эревнометрического подхода к изучению предметного содержания. Выделяются ориентировочные теоретические принципы учебно-исследовательской деятельности, реализующей интегративные принципы субъектности, базисной активности, орудийной адекватности, технологической значимости, предметного соответствия, мориторинговое соотношение $[9,10]$.

Это порождает формирование реального эревнометрического процесса, направленного на раскрытие всего цикла исследовательского анализа, который реализуется через последовательное выполнение соответствующих действий направленных на выделение: всеобщего эревнометризма; его порождающего содержания; внешних параметров, отражающих пространственно-временные и базисные социальные параметры; сложность эревнометрического анализа; общая схема, формирующая заданный процесс; структурные элементы, реализующие данную функциональную сложность; функциональное состояние логических процессов; характеристик передаточных функций; порождающие процессы развития сложности относительных параметров; внешнее выражение целевых отношений; внутренний микроскопический анализ математических образов через их сложность, разнообразие и упорядоченность; статическое и динамическое состояние учебного материала относительно временных характеристик учебного процесса; формирование футуристических форм учебно-исследовательских умений в развитии познавательной активности $[11,12]$.

Совершенствование эревнометрического анализа учебноисследовательских умений студентов в процессе изучения курса высшей математики происходит в результате проработки многофазных элементов учебно-исследовательской деятельности, которая зарождается в условиях воспитания смысла прогнозируемой активности через ознакомление c совершенными формами нормативного исследовательского умения с широким диапазоном решаемых учебных задач многопредметного содержания, которые приобретают заданный уровень интереса к 
проецируемому учебному

материалу

мотивационной формы $[13,14]$.

Это позволяет совершить переход к началу самостоятельного освоения эревнометрического анализа математических объектов высокой формы алигорамого содержания и формы. Учащимся сообщается учебная информация относительно всеобщи процессов исследовательской активности через последовательность эревнометрических действий, направленных на уяснение особенностей познавательной активности.

Возникающая самостоятельная эревнометрическая деятельность начинается с материальных объектов различного содержания и формы, которые формируют реальную чувствительности происходящих процессов. То есть существует предкомпьютерная форма учебно-исследовательской деятельности, которая регламентирует основы развития оперативного мышления алигорамого содержания $[15,16]$.

Материальные математические эревнометрические объекты позволяют формировать нормативное содержание учебноисследовательского умения, направленного на воспитание высших форм психологопедагогического отношения ко всему развитию эревнометрического субъекта алигорамого содержания.

Тезис о единстве мышления и речи позволяет раскрыть основные формы фонетического содержания эревнометрического анализа. При этом формируется особенная языковая среда, отражающая возможности организации коммуникативной деятельности, обеспечивающей качественное общение между субъектами учебно-исследовательскообразовательной деятельности. Возникающий язык эревнометрического анализа отражает номинальный фонетический образ обобщённого эревнометрического объекта.

Формирование

целостного эревнометрического образа образовательного объекта математического содержания непрерывно связано с графическим представлением логических отношений. Это требует формирования адекватной теории знаковых образов алигорамной направленности.

Множество знаковых образов должно отражать всю логическую последовательность эревнометрической деятельности алигорамного содержания. Каждый знак должен отражать сложную структуру каждого шага учебноисследовательского умения, как закреплённого образа субъектного содержания.

Можно выделить обобщённые знаки эревнометрического цикла образовательной деятельности, которые должны иметь смысл математических процессов. $\mathrm{K}$ таким знакам можно отнести: знак субъекта математического анализа; образ обобщённого эревнометрического процесса; иконос средств исследовательской деятельности; знак специфического математического алгорамного содержания; образ предметного содержания эревнометрического процесса; иконос процесса тождественности исследовательской деятельности; образ результата эревнометрического процесса. Это позволяет организовать начальный этап организации эревнометрического анализа математических объектов.

Аналогичный подход применяется к множеству действий эревнометрического анализа алигорамного содержания, отражающего единство смыслообразования эревнометрического действия; его принятие; выполнение ориентировочной части; собственное исполнительние действия; проведение контроля выполненного действия; анализ прогноза развития действия алигорамного содержания.

Фазовое развитие эревномертического анализа математической подготовки учащихся требует выполнение множества логических операций в умственной форме, что является естественным содержанием учебноисследовательских умений высшего уровня образовательных объектов личностного развития учащихся.

\section{Conclusion}

Рассмотренные основны проблемы исследования организации эревнометрического анализа учебно-исследовательских умений студентов в процессе изучения курса высшей математики неразрывно связаны с современными моделями организации производства в базисной форме, моделирующей данную исселедовательскую задачу, решаемую через этапы активации процесса познания: установление всеобщей схемы процесса эревнометрического анализа учебноисследовательских умений студентов; определение метода моделирования проблемы формирования эревнометрического анализа учебно-исследовательских умений студентов; установление формы заданного результата эревнометрического анализа учебноисследовательских умений студентов. Это позволяет определить эревнометрический анализ оптимальных учебно-исследовательских умений по формированию знаний студентов в процессе изучения курса высшей математики алигорамного типа. 


\begin{tabular}{|c|c|c|c|c|c|c|}
\hline Impact Factor: & $\begin{array}{l}\text { ISRA (India) } \\
\text { ISI (Dubai, UAF } \\
\text { GIF (Australia) } \\
\text { JIF }\end{array}$ & $\begin{array}{l}=1.344 \\
=0.829 \\
=0.564 \\
=1.500\end{array}$ & $\begin{array}{l}\text { SIS (USA) } \\
\text { PИНЦ (Russia) } \\
\text { ESJI (KZ) } \\
\text { SJIF (Morocco) }\end{array}$ & $\begin{array}{l}=0.912 \\
=0.234 \\
=3.860 \\
=\mathbf{2 . 0 3 1}\end{array}$ & $\begin{array}{l}\text { ICV (Poland) } \\
\text { PIF (India) } \\
\text { IBI (India) }\end{array}$ & $\begin{array}{l}=6.630 \\
=1.940 \\
=4.260\end{array}$ \\
\hline
\end{tabular}

\section{References:}

1. Tokmazov GV (2014) Matematicheskoe modelirovanie $\mathrm{v}$ uchebno-professional'noy deyatel'nosti. Materialy Mezhdunarodnoy nauchnoy konferentsii «Modern mathematics in science» - 30.06.2014. ISJ Theoretical \& Applied Science 6(14): 44-46. - Caracas, Venezuela. doi: http://dx.doi.org/10.15863/TAS.2014.06.14.8

2. Tokmazov GV (2014) Mathematical modeling research skills in educational activity methods of probability theory. Materialy Mezhdunarodnoy nauchnoy konferenctsii "Eurapean Science and Technology" 30.11.2014. ISJ Theoretical \&Applied Science 11(20): 66-69 Southampton, United Kingdom. doi: http://dx.doi.org/10.15863/TAS.2014.11.19.13

3. Tokmazov GV (2014) Matematicheskoe modelirovanie $\mathrm{v}$ uchebno-professional'noy deyatel'nosti // Materialy Mezhdunarodnoy nauchnoy konferenctsii "Modern mathematics in science" - 30.06.2014. ISJ Theoretical \&Applied Science 6(14): 44-46 Caracas, Venezuela. doi: http://dx.doi.org/10.15863/TAS.2014.06.14.8

4. Tokmazov GV (2016) Analysis says study skills in the study of mathematics// Materialy Mezhdunarodnoy nauchnoy konferenctsii "Eurapean Science and Education" 30.07.2014. ISJ Theoretical \&Applied Science 6(14): 72-74 Marseille, France. doi: http://dx.doi.org/10.15863/TAS.2014.06.14.9

5. Tokmazov GV (2014) Mathematical modeling research skills in educational activity methods of probability theory// Materialy Mezhdunarodnoy nauchnoy konferenctsii "Eurapean Science and Technology" 30.11.2014. ISJ Theoretical \&Applied Science 11(19): 66-69 Southampton, United Kingdom. doi: http://dx.doi.org/10.15863/TAS.2014.11.19.13

6. Tokmazov GV (1994) Zadachi dinamicheskogo xaraktera // Matematika v shkole. - 1994. - № 5.- p.9-12.

7. Tokmazov GV (1999) Ukrupnenie didakticheskix edinic $\mathrm{v}$ zadachax po teorii veroyatnostej// Matematika v shkole. - 1999. № 4.- p.81-85.

8. Tokmazov GV (1999) Model formirovaniya issle-dovatelskix umenij na osnove tryoxkomponentnoj strukture umstvennogo dejstviya // Nauchnye trudy Moskovskogo pedagogicheskogo gosudarstvennogo universiteta. Seriya: Estestvennye nauki. - M.: Prometej, 1999. - p.68-88.

9. Tokmazov GV (2013) Sistematizaciya i differen-cirovannyj podxod pri obuchenii resheniyu zadach nachal teorii veroyatnostej: monografiya. - 2-e izd., dop.i isprav. Novorossijsk: GMU imeni admirala F.F.Ushakova, 2013. - 176 p. - ISBN 978-589426-071-6

10. Tokmazov GV (2014) Opredelenie uslovij podgotovki uchashhixsya $\mathrm{k}$ organizacii issledovatelskix umenij pri obuchenii matematike// Kazanskaya nauka. 2014. № 7. p. 180-185

11. Tokmazov GV (2014) Matematicheskoe modelirova-nie issledovatelskix umenij metodami setej Petri // Materialy Mezhdunarodnoy nauchnoy konferenctsii "Eurapean Science and Technology" 30.11.2014. ISJ Theoretical \&Applied Science 12 (20): 56-59 Birmingham, United Kingdom. doi:

http://dx.doi.org/10.15863/TAS.2014.12.20.13

12. Tokmazov GV (2015) Bazisnye usloviya modeliro-vaniya issledovatelskix umenij $\mathrm{v}$ processe izucheniya matematiki// Vysshee obrazovanie segodnya. - 2015. - № 7.- p.12-15.

13. Mishchik SA (2014) Mathematical modeling system integrity-curricular activities - the second problem pedagogometriki. Materialy Mezhdunarodnoy nauchnoy konferenctsii "European Innovation" - 30.09.2014. ISJ Theoretical \&Applied Science 9(17): 126-128 Martigues, France. doi: http://dx.doi.org/10.15863/TAS.2014.09.17.21

14. Mishchik SA (2014) Mathematical modeling holistic-systemic communicative activity - the third task pedagogometriki. Materialy Mezhdunarodnoy nauchnoy konferenctsii "European Scientific Achievements" 30.10.2014. ISJ Theoretical \&Applied Science 10(18): 45-47 Brighton, UK. doi: http://dx.doi.org/10.15863/TAS.2014.10.18.11

15. Mishchik SA (2014) Mathematical modeling integrity - system performance subject - fourth task pedagogometriki. Materialy Mezhdunarodnoy nauchnoy konferenctsii "Eurapean Science and Technology" 30.11.2014. ISJ Theoretical \&Applied Science 11(19): 51-54 Southampton, UK. doi: http://dx.doi.org/10.15863/TAS.2014.11.19.10 


\begin{tabular}{l|lrl|l|ll} 
& ISRA (India) & $=\mathbf{1 . 3 4 4}$ & SIS (USA) & $=\mathbf{0 . 9 1 2}$ & ICV (Poland) & $=\mathbf{6 . 6 3 0}$ \\
Impact Factor: & ISI (Dubai, UAE) $=\mathbf{0 . 8 2 9}$ & PUHL (Russia) $=\mathbf{0 . 2 3 4}$ & PIF (India) & $=\mathbf{1 . 9 4 0}$ \\
& GIF (Australia) & $\mathbf{0 . 5 6 4}$ & ESJI (KZ) & $=3.860$ & IBI (India) & $=\mathbf{4 . 2 6 0}$ \\
& JIF & $\mathbf{1 . 5 0 0}$ & SJIF (Morocco) & $=\mathbf{2 . 0 3 1}$ & & \\
\hline
\end{tabular}

16. Mishchik SA (2015) Pedagogometrik - science and academic subject. Materialy Mezhdunarodnoy nauchnoy konferenctsii "European Technology in Science"
28.02.2015. ISJ Theoretical \& Applied Science 02 (22): 103-106 Malmö, Sweden. doi:

http://dx.doi.org/10.15863/TAS.2015.02.22.17 